\title{
2011 TMS President Garry Warren: Looking Ahead to a Productive Year
}

\author{
Garry Warren
}

As the newly inducted 2011 president of TMS, I'm pleased to have this opportunity to introduce myself to you

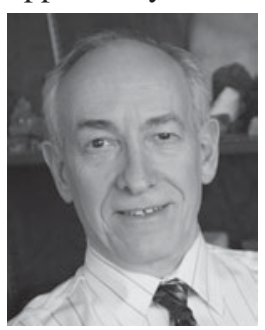
and share with you some of my thoughts on the near- and longterm prospects for our Society.

First, though, I'd like to take a look back at how I arrived in this position. We all have a story about how we found our way to careers in materials science. Mine had its earliest start not in a classroom but in a kitchen. . . a military kitchen, to be exact. My father was an army mess sergeant and chef, and did not realize he was providing an example of science in action as he combined ingredients, some highly unattractive to a youngster, and transformed them into something entirely new-and delicious. I did not realize it at the time, but now I know that the processes and chemistry in cooking really appealed to me.

In school, I enjoyed math and science, so I began my undergraduate studies at the University of Texas at El Paso (UTEP), as a math major with a chemistry minor. Then, another, very practical, influence came into play: I needed a job. While I was an undergraduate I had a childhood friend who was studying metallurgical engineering. Every year he got a great summer job and I didn't. After a year or two, I changed majors. I had great summer jobs after that.

After a few years in the steel industry and an M.S. at UTEP, I went to the University of Utah for my Ph.D., where I had the great pleasure of having Milt Wadsworth as my advisor. He was an active TMS member and future president.

Currently, I am a professor in the De- partment of Metallurgical and Materials Engineering at The University of Alabama, Tuscaloosa, Alabama, and very much enjoying where my career path led me. The research has been quite interesting. My areas of focus are electrochemistry and corrosion, and earlier in my career, hydrometallurgy. And I love teaching; it's the main reason I became a professor. I enjoy interactions with students, seeing the light bulbs go on.

I am greatly impressed with the young people I see at our meetings and in my classes. They have a passion to make meaningful contributions to our society, TMS, as well as our society beyond TMS. For TMS to flourish we must harness that passion.

And that is where I see our near- and long-term future developing, around the issues and ideas that are important to this new generation of materials scientists and engineers. The TMS Board of Directors has been very proactive in this regard. One initiative intended to move TMS progressively along this path is the Materials \& Society concept of homing in on ways materials science can benefit society as a whole. This effort is of sufficient importance that a TMS Materials $\&$ Society committee was created, and it is populated with passionate, motivated and active volunteers.

Also, if you peruse the annual meeting program, you'll find a wide variety of programming options that speak to the Materials and Society theme, including symposia pertaining to reducing carbon dioxide emissions, improving furnace efficiency, recycling electronic wastes, and many others.

I envision a year where this programming area grows to even greater levels of activity with greater volunteer involvement. And I'd like to see TMS help disseminate the word on our activi- ties and successes in materials and society matters. I think we as a Society and as a profession need to make our case to the public about what it is we do and its importance. We need to interpret what we do for public consumption, first so students are aware of this TMS priority, and also, so the general public can grasp the significance of materials science and engineering in our lives.

Another area where I'm looking forward to ongoing focus is the expansion of TMS's international reach. In recent years we've formalized relationships to the north and the south of our U.S. headquarters with the Alliance of the Americas. I'd like to see continued active engagement with colleagues in North and South America, as well as materials societies on other continents. TMS is an international society, and we all benefit greatly from relationships with our colleagues around the globe.

In an even broader context, in the coming year you will see efforts to reexamine the TMS Strategic Plan. To remain vital and relevant, any organization must periodically reflect on its overall mission and how it will achieve that mission.

It's important to keep in mind that none of these initiatives can succeed without strong volunteer commitment. So please, get involved. In fact, this year you'll notice stepped-up efforts to connect members with volunteer opportunities. There is much to be done in the coming years, and together we can accomplish so much more.

Garry Warren is a professor in the Department of Metallurgical and Materials Engineering at the The University of Alabama Tuscaloosa, Alabama and the 2011 TMS president. 